\title{
Maternal Mortality Ratio in Eastern Mediterranean Region: A Priority of Reproductive Health
}

\author{
Fatemeh Nahidi $^{\circledR}$, Mahboubeh Hajifoghaha ${ }^{2^{* \mathbb{D}}}$
}

\begin{abstract}
Objectives: Maternal mortality reduction is a key international sustainable development goal. Although maternal mortality ratio (MMR) has changed in the Eastern Mediterranean Region, the trend of maternal deaths in the countries of the region is important. This review article provided the current situation and trend of MMR in the Eastern Mediterranean region between 1990 and 2015. Materials and Methods: In this review, country profiles and data were obtained through UNDPA, UNICEF, UNDP, WHO, and World Bank websites. Then, a literature search was performed in PubMed, Science Direct, Scopus, and Google Scholar in this regard. Results: Based on the collected data, 36 out of 66 studies met the required criteria and were chosen for analysis. All countries of this region showed a downward trend between 1990 and 2015, and this change varied from 16.30\% in Yemen to 76.56\% in Lebanon. The maternal mortality reduction was $69.88 \%$ in Iran in the same time.

Conclusions: Although all countries of the Eastern Mediterranean Region demonstrated a downward trend in MMR, this trend was not the same in all countries. Thus, it is needed to boost regional efforts to further reduce MMR and achieve sustainable development goals by 2030 .

Keywords: Eastern Mediterranean, Iran, Maternal mortality, Reproductive health
\end{abstract}

\section{Introduction}

Pregnancy is one of the most critical periods for women (1) and $15 \%$ of pregnancies threaten their life (2). According to the World Health Organization (WHO)ICD10 (International Statistical Classification of Diseases), imposing a tragedy for a woman's family and society (3), maternal mortality is defined as the death of a woman during pregnancy or up to 42 days after pregnancy termination from any cause related to or aggravated by the pregnancy or its management, but not from accidental or incidental causes (4). Maternal mortality ratio (MMR) defines the number of maternal deaths during a given period of time per 100000 live births (5).

In 2013, a total of 290000 maternal mortalities were reported worldwide (6), 99\% of which occurred in low- and middle-income countries (7). The definition of maternal mortality allows for the identification of maternal deaths on the basis of their causes (8). This is used as a measure of the quality of a health care system (9).

Maternal mortality was specifically targeted by the WHO Millennium Development Goal 5 (MDG-5) which required reducing the MMR by three quarters between 1990 and 2015 (10). Other international agencies of the United Nations showed a reduction in maternal mortality globally, but it seems that the rate of the progress is inadequate (11), as was indicated by a reduction of as low as $45 \%$ in the MMR between 1990 and 2013 (6). In other words, this ratio reduced by $2.6 \%$ per year which was far from the annual decline of $5.5 \%$ required to achieve the MDGs (9). In 2015, the MDG era came to a close and a new agenda was set that focused on sustainable development goals (SDGs). The world is now embarking on the set of health commitments under the SDGs, including ending all preventable maternal deaths by 2030 (12). The maternal mortality reduction is a key international SDG (13).

Accordingly, there is a need for contributing to the global effort for eradicating needless deaths from pregnancy and childbirth (2). The global MMR, which was 216 in 2015, must be reduced to less than 70 per 100000 live births, according to SDG 3.1 (14). In 2015, MMR was 166 across the Middle East (15).

A review on maternal death helps define the problem, determine its scope, as well as identify the factors involved in and those leading to the problem (16). Many of the reported maternal deaths and injuries are preventable entirely $(17,18)$. The findings showed that having more than four pregnancies, poor prenatal care, inhabitation in a rural and remote area, far distance to emergency obstetrician facilities, and maternal illiteracy were the most important determinants of maternal mortality (19).

The findings of another study demonstrated a significant positive association between cesarean delivery and 
maternal death. Importantly, the death was related to the indication of cesarean delivery in most cases rather than the operation itself (20). Some research reported bleeding as the most prevalent cause of maternal death $(19,21)$.

Eradicating preventable maternal deaths worldwide requires several changes such as eliminating gender inequalities and building stronger health systems (2). An important requirement for reducing the count of maternal deaths is to understand the causes of the deaths, according to which one can set for effective policies, make decisions on efficient health programs (8), and undertake necessary interventions to control the problem and prevent any future reoccurrence (16). The strategies already proved to be effective for reducing or eliminating the causes in other countries shall be identified as well (22).

This article provided a background on the current situation of MMR in the Eastern Mediterranean Region, including the causes of and contributing factors into the problem, and described strategic directions aimed at accelerating the reduction of maternal mortality in the Region and moving toward the SDGs.

\section{Materials and Methods}

In this review, Eastern Mediterranean countries (Figure 1) were selected based on the WHO categorization of countries into different regions. According to this classification, the region is composed of 21 countries (23).

Country profiles and related reports to this research were obtained through the United Nations Department of Political Affairs (UNDPA), United Nations Children's Fund (UNICEF), United Nations Development Programme (UNDP), WHO, and the World Bank websites. Then, a literature search was performed on several scientific databases including PubMed, Scopus, Science Direct, and Google Scholar. Additionally, the reference lists of the included studies and relevant reviews were searched for eligible studies. Following the definition proposed by the WHO, maternal mortality was considered as the death of a woman during pregnancy or up to 42 days after delivery irrespective of the site and duration of the pregnancy.

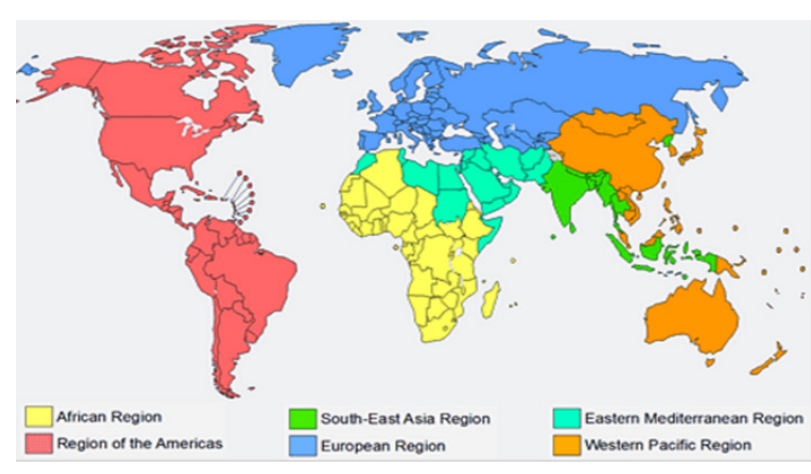

Figure 1. Map of the Eastern Mediterranean Region.

Note. The definition adopted in the review included Afghanistan, Bahrain, Djibouti, Egypt, Iran, Iraq, Jordan, Kuwait, Lebanon, Libya, Morocco, Oman, Pakistan, Qatar, Saudi Arabia, Somalia, Sudan, Syria, Tunisia, the United Arab Emirates, and Yemen.
The definition includes deaths from any cause related to or aggravated by pregnancy and its management, but not those from accidental or incidental causes (24).

In addition, various data were used, including $\mathrm{MeSH}$ headings, text words, and word variants for "maternal mortality" or "maternal death", followed by combining them with the term "eastern Mediterranean countries" or "Middle East" or the names of the countries. These were further combined with the terms related to "pregnant women".

Some studies were included that assessed the maternal mortality in Eastern Mediterranean countries and were published any time between 2002 and 2017. The authors excluded the studies in other regions, non-English articles, and those published before 2002. A manual search for textbooks was conducted as well.

\section{Study Selection}

The titles and abstracts of all articles were identified by two authors who then reached a consensus on the potential eligibility of each article. Further, the full texts of relevant records were retrieved and assessed for eligibility.

The used documents (i.e., papers, conference abstracts, and country profiles) represented the findings of this study. The findings duplicated in more than one report were included only once.

\section{Data Extraction}

The data during 1990-2015 were extracted from the World Bank and WHO websites. The details of the search criteria are provided in Figure 2. The data were then imported into a computerized database and extracted by the authors.

\section{Data Synthesis}

The findings were subjected to a quantitative synthesis. For this purpose, the percent change and average annual percent change in MMR were calculated between 1990 and 2015 .

Percent change between 1990 and $2015=$ $\left(\frac{M M R 2015-M M R 1990}{M M R 1990}\right) \times 100$

Average annual percent change $=$ $\left[\left(\frac{M M R 2015}{M M R 1990}\right)^{\frac{1}{2015-1990}}-1\right] \times 100$

The countries with MMR $\geq 100$ in 1990 were categorized to determine their progress toward improving maternal health as follows:

- "On track" if MMR had 5.5\% or more average annual decline;

- "Making progress" if MMR had 2\% to 5.5\% average annual decline;

- "Insufficient progress" if MMR had less than 2\% 


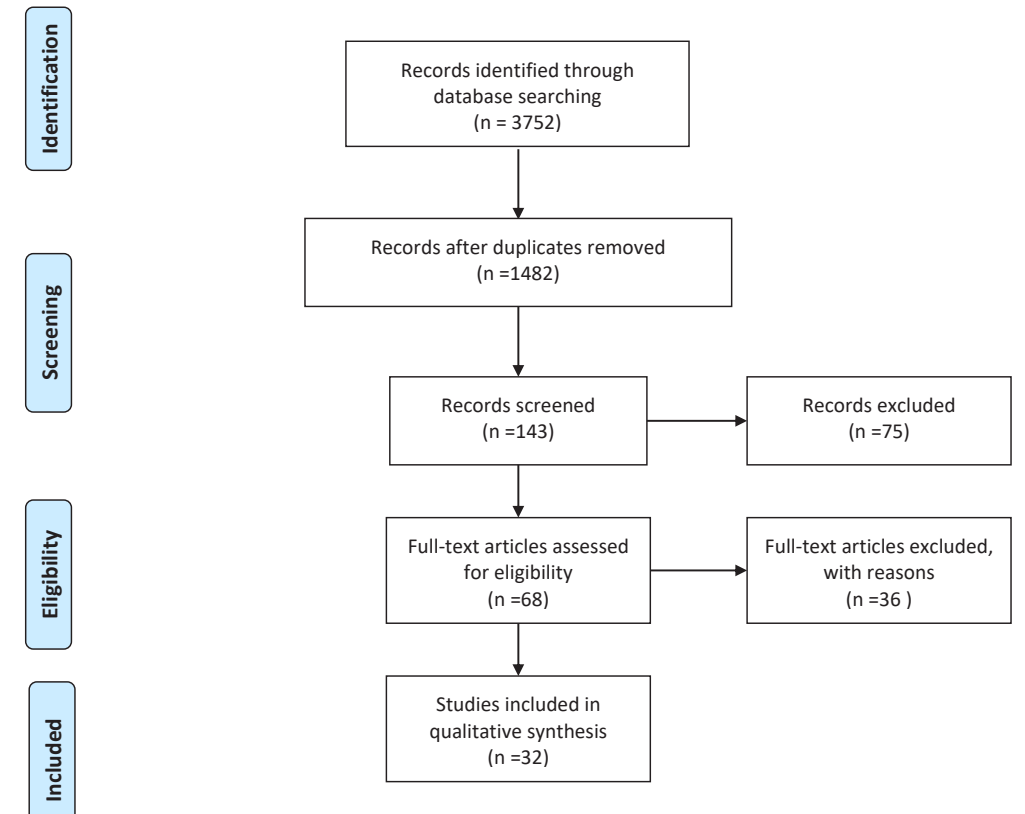

Figure 2. Flowchart of Study Selection.

average annual decline;

- "No progress" if MMR experienced an average annual increase.

Countries with MMR $<100$ were not categorized (5, 25, 26).

The statistical analyses were done by SPSS software, version 23. The Fisher exact test was used to determine the significance of the trend of maternal mortality ratios. Accordingly, an MMR with any $P \leq 0.05$ was considered statistically significant.

\section{Results}

Most recently (2015), the MMRs related to global and Eastern Mediterranean regions have been reported to be $216 / 100000$ and $166 / 100000$, respectively. The corresponding figure to the Eastern Mediterranean countries in 1990 was $340 / 100000$ (14), indicating a mean reduction of 54\% from 1990 to $2015(27,28)$, the related data of which are shown in Figure 3.

In addition, the average annual percent change in the MMR was 3.16 during the same period. Most of the countries in the Eastern Mediterranean region have middle income (27).

No significant difference is observed between the MMRs of Bahrain and Qatar in either 1990, 2013, or 2015 based on the results of Fisher exact test $(P \geq 0.05)$.

All countries in the Eastern Mediterranean region show a downward trend regarding maternal mortality, but there are large variations in the MMRs between different countries. On the other hand, although all eastern Mediterranean countries contributed to the global reduction in the MMR, data pointed to the success stories of several countries during the past decades. The rate of maternal deaths reduced by $75 \%$ and above in Lebanon thus, the country achieved the MDG5 while the lowest decline in MMR was observed in Yemeni women (16.30\%) between 1990 and 2015 (Table 1). There was a decreasing MMR trend in Iran from 83 in 1990 to 25 in 2015.

\section{Discussion}

This article provided a background on the current situation of MMR in the Eastern Mediterranean Region and described strategies that can be implemented to improve women's health status. In recent years, the reduction in MMR is an international health priority. Considering different factors affecting public health issues (29), the maternal mortality indicator reveals huge

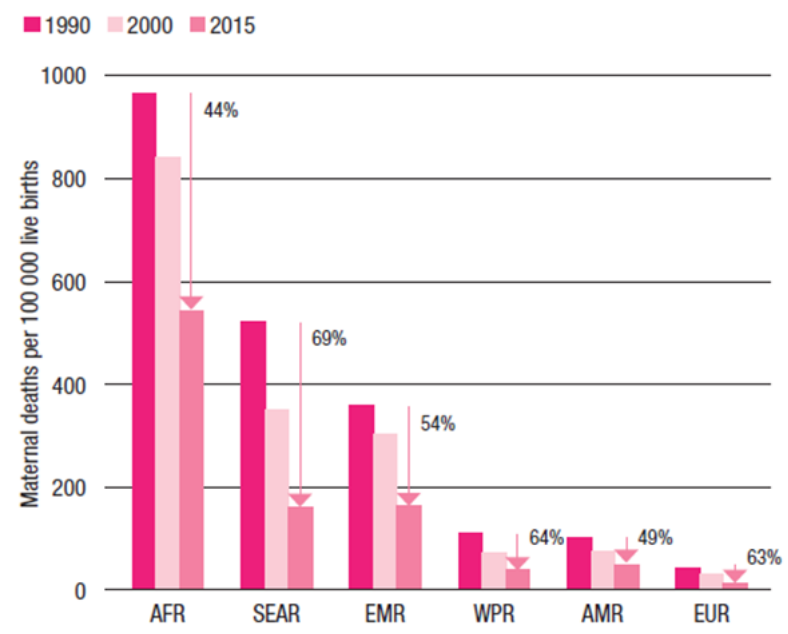

Figure 3. Trends in the Maternal Mortality Ratio by the WHO Region (1990-2015). 
Table 1. Trends of Maternal Mortality Ratio by Country During 1990-2015

\begin{tabular}{|c|c|c|c|c|c|c|c|c|}
\hline \multirow[b]{2}{*}{$\begin{array}{l}\text { Eastern } \\
\text { Mediterranean } \\
\text { Countries (28) }\end{array}$} & \multicolumn{6}{|c|}{ Maternal Mortality Ratio (Per 100000 Live Births) } & \multirow[b]{2}{*}{$P$ Value } & \multirow[b]{2}{*}{ Income (27) } \\
\hline & $\begin{array}{l}1990 \\
(25)\end{array}$ & $\begin{array}{l}2013 \\
(25)\end{array}$ & $\begin{array}{l}2015 \\
(26)\end{array}$ & $\begin{array}{l}\text { Percent of Change } \\
\text { Between } 1990 \text { and } \\
2015\end{array}$ & $\begin{array}{c}\text { Average Annual \% } \\
\text { Change in MMR } \\
\text { Between } 1990 \text { and } 2015\end{array}$ & $\begin{array}{c}\text { Progress Toward } \\
\text { Improving Maternal } \\
\text { Health (5) }\end{array}$ & & \\
\hline Afghanistan & 1200 & 400 & 396 & -67.00 & -4.34 & Making progress & $<0.001$ & Low \\
\hline Bahrain & 21 & 22 & 15 & -28.57 & -1.34 & - & 0.506 & High \\
\hline Djibouti & 400 & 230 & 229 & -42.75 & -2.21 & Making progress & $<0.001$ & Lower middle \\
\hline Egypt & 120 & 45 & 33 & -72.50 & -5.03 & Making progress & $<0.001$ & Lower middle \\
\hline Iran & 83 & 23 & 25 & -69.88 & -4.69 & - & $<0.001$ & Upper middle \\
\hline Iraq & 110 & 67 & 50 & -54.55 & -3.11 & Making progress & $<0.001$ & Upper middle \\
\hline Jordan & 86 & 50 & 58 & -32.56 & -1.57 & - & 0.005 & Upper middle \\
\hline Kuwait & 12 & 14 & 4 & -66.67 & -4.30 & - & 0.047 & High \\
\hline Lebanon & 64 & 16 & 15 & -76.56 & -5.64 & - & $<0.001$ & Upper middle \\
\hline Libya & 31 & 15 & 9 & -70.97 & -4.83 & - & 0.001 & Upper middle \\
\hline Morocco & 310 & 120 & 121 & -60.97 & -3.69 & Making progress & $<0.001$ & Lower middle \\
\hline Oman & 48 & 11 & 17 & -64.58 & -4.07 & - & $<0.001$ & High \\
\hline Pakistan & 400 & 170 & 178 & -55.50 & -3.19 & Making progress & $<0.001$ & Lower middle \\
\hline Qatar & 11 & 6 & 13 & 18.18 & 0.68 & - & 0.262 & High \\
\hline Saudi Arabia & 41 & 16 & 12 & -70.73 & -4.80 & - & $<0.001$ & High \\
\hline Somalia & 1300 & 850 & 732 & -43.69 & -2.27 & Making progress & $<0.001$ & Low \\
\hline Sudan & 720 & 360 & 311 & -56.81 & -3.30 & Making progress & $<0.001$ & Lower middle \\
\hline Syria & 130 & 49 & 68 & -47.69 & -2.56 & Making progress & $<0.001$ & Lower middle \\
\hline Tunisia & 91 & 46 & 62 & -31.87 & -1.52 & - & $<0.001$ & Lower middle \\
\hline UAE & 16 & 8 & 6 & -62.50 & -3.85 & - & 0.072 & High \\
\hline Yemen & 460 & 270 & 385 & -16.30 & -0.71 & Insufficient progress & $<0.001$ & Lower middle \\
\hline
\end{tabular}

Note. MMR: Maternal mortality ratio.

disparities between different countries (30).

The MMR should be reduced to less than 70/100000 live births in order to terminate preventable maternal mortality by 2030 , the global annual rate of reduction will need to be at least $7.3 \%$ (15) and appropriate strategies shall be undertaken to prevent maternal deaths, as it is planned in many countries (31).

The data derived from the health information system of Iran showed a decreasing trend in the MMR (32), and researchers claimed that Iran has achieved a dramatic decline in the MMR so that the current rate is comparable with that of developed countries. Furthermore, Iran has experienced a significant paradigm shift in the major causes of maternal mortality from those which are the characteristics of developing nations (i.e., postpartum hemorrhage and infection) to causes which are more common in developed nations, such as a pulmonary embolus and stroke (33). Some studies indicated that bleeding was the most common cause of maternal death in $\operatorname{Iran}(34,35)$.

The MMR decreased from 83 in 1990 to $25 / 100000$ live births in 2013 in Iran (25). This rate needs to be decreased as much as possible (36). The results of a study on maternal mortality reports in Iran showed that there is a gap between the policies and actual practices, which can be attributed to inadequate training programs, inadequate collaboration, and the lack of guidelines into maternal deaths (31). Fortunately, data gathering by the maternal mortality surveillance system has been of satisfactory quality because of continuous supports and supervision (37). To reduce maternal deaths, Iran has made efforts such as significant improvement in skilled attendance, antenatal care, and family planning (31).

The results of a cross-sectional study on 668 mothers revealed that an increase in the population of midwives in the family physician program led to increased women's awareness of the benefits of natural childbirth (38). Other strategies for the reduction of maternal deaths included improving the quality of hospital services and out-patient emergency obstetric cares, increasing the coverage and quality of family planning services provided, especially for high-risk mothers, extending access to emergency obstetric care and preventing delays in referring highrisk cases, and enhancing public awareness on emergency obstetric cares $(37,39)$.

According to the latest report by the WHO, MMR in Afghanistan was 396/100000 live births in 2015 as compared to $1200 / 100000$ in 1990 (26). Over the past decade, the implementation of several maternal care interventions has increased antenatal care (16\% to 53\%), skilled birth attendance ( $14 \%$ to $46 \%)$, and births in a health facility (13\% to $39 \%)$ in Afghanistan. According

4 | International Journal of Women's Health and Reproduction Sciences, Vol. 8, No. 1, January 2020 
to Akseer et al (40), the number of deployed facilities and community-based health-care professionals also increased during 2005-2013, including nurses (738 to $5,766)$, midwives (211 to 3333), general physicians (403 to 5990), and community health workers (from 2682 to 28837). The results of another study showed that the SWOT analysis can be used to design and implement the Basic Package of Health Services so that to reduce maternal mortality in Afghanistan (41). The researchers who assessed MMR-related health needs in Afghanistan suggested that programs and interventions should be designed for reducing the alarming rates in this country which has experienced decades of war and suffers disparities in women's health and education (42).

Based on the findings, the MMR in Bahrain changed by $28.57 \%$ between 1990 and $2015(25,26)$. The aim of a report from Bahrain was to identify preventable factors contributing to maternal deaths. In this audit of care, $28.3 \%$ of maternal deaths were found to be avoidable, nearly half of which was due to a shortage of intensive care beds. Thus, the authors recommended to conduct a confidential enquiry on maternal deaths every three to five years at the national level (43).

In Egypt, the average annual MMR was found 5.03\% between 1990 and $2015(25,26)$. In a study performed to identify the causes and predisposing factors to maternal deaths in Egypt, delay in seeking medical advice and substandard medical care were recognized as the two main factors contributing to recorded maternal deaths (44). Another study considered Egyptian women at low risk and found anesthesia responsible for maternal death (45). In a retrospective cohort study in Egypt, researchers found that the avoidable causes of maternal mortality accounted for $61.8 \%$ of the mortality cases. According to this research, obstetric hemorrhage was the leading cause of maternal mortality in Egypt, followed by the delay in seeking medical advice by women or their families, and delayed referral from other hospitals (21).

Another retrospective analysis of maternal deaths in a Kuwait tertiary teaching hospital was performed during 1980-2009. The results showed that although maternal mortality rates decreased significantly during the studied 29-year period, substandard care was identified as contributing to $70 \%$ of direct and $55 \%$ of indirect deaths (46). According to the WHO, the MMR has decreased by 66.67\% in Kuwait between 1990 and $2015(25,26)$.

In Morocco, MMR reportedly changed by $60.97 \%$ between 1990 and $2015(25,26)$. A survey on maternal deaths in Morocco in 2009 pinpointed that more than half of the maternal deaths were associated with substandard care in the hospitals. The main avoidable factors were insufficient follow-up of care, inadequate treatment, and the delay by the families in seeking care (47).

Similarly, Oman had an average annual decrease of 4.07\% in MMR from 1990 to $2015(25,26)$. The researchers of a population-based study suggested that evidencebased counseling should be facilitated for older expectant mothers to decrease adverse pregnancy outcomes in advanced maternal age (48). The study recommended a framework for national strategic directions to scale up the access to essential interventions so that to reduce maternal mortality in Oman, moving closer to the achievement of the MDGs (16).

In Pakistan, for decreasing MMR, should ensure that the quality of care is adequate and interventions are capable of leading to significant reductions in maternal mortality (49). Further, maternal death can be effectively managed by skilled care during pregnancy, childbirth, and the postnatal period (50). Pakistan succeeded to change its MMR by $55.50 \%$ from 1990 to $2015(25,26)$.

According to this research, even though the MMR of Qatar was 11/100 000 in 1990, it increased to approximately $13 / 100000$ in $2015(25,26)$. The WHO classified Qatar under the countries with no good-quality national data on maternal mortality, but Rahman et al. confirmed that the MMR of Qatar has decreased from 1990 to 2012 (51).

Moreover, Saudi Arabia had an average annual decrease of $4.80 \%$ in MMR from 1990 to $2015(25,26)$. The researchers concluded that a reduction in MMR in Saudi Arabia was envisaged through greater patient acceptance of medical advice, family spacing, and proficient obstetric services (52).

Aiming at reducing MMR, Somalian researchers recommended, based on their findings, that the central government should take steps to elevate vulnerable population's incomes to such an extent that pregnant women could afford accessing health facilities. Additionally, women should be educated and provided with employment opportunities in order to reduce fertility rate (9). Although Somalia succeeded in decreasing the MMR by $43.69 \%$ between 1990 and 2015, it was still less than that set in the fifth target of the MDGs $(25,26)$. Similarly, a situation analysis in Somalia revealed that more than $90 \%$ of women delivered at home and more than half of them were assisted by a traditional birth attendant, indicating poor access to skilled delivery care and emergency obstetric care. Moreover, rural and nomadic population were found to have no access to timely obstetric interventions and there was a major lack of required facilities to handle basic emergency obstetric care. In addition, referral centers for caesarean sections (C-sections) were under-utilized and the services were of poor quality with a high case fatality rate. Only one out of each four Somalian pregnant women attended antenatal care where services were of poor quality (53).

Likewise, Sudan succeeded in reducing the MMR by 56.81\% between 1990 and 2015 (25,26). In Sudan, similar to many other African countries, there are documented successes in improving the quality of care, as well as increasing the client satisfaction and use of available 
services. Maternal death challenges are mainly inadequate resources, poor budget, limited untrained staff, frequent turnover, and limited awareness on the importance of the notification of maternal death and reporting of live birth (54). A study suggested that more efforts should be made for reducing maternal and perinatal mortality. More care should be taken toward nutrition and preventing malaria and other communicable diseases (55).

The WHO reported an average annual change of $2.56 \%$ for MMR in Syria between 1990 and 2015 (25,26). A Syrian study indicated that there is an urgent need for developing national protocols to regulate practices during the third stage of labor and the postpartum period (56). It was reported that the causes of maternal mortality and their contributing factors in Syria reflect serious defects in the quality of maternal care that need to be rectified urgently. This research showed that Syria and Sudan have made progress toward improved maternal mortality (57).

In a cross-sectional study on maternal near-miss cases maternal mortality indices were compared together in four major public hospitals in Egypt, Lebanon, Palestine, and Syria in 2011. Hemorrhage-related complications were the most frequent causes of the maternal near-miss cases across the four hospitals and the findings confirmed the need for quality improvement interventions (58).

In Tunisia, the MMR reportedly decreased from 91 in 1990 to 62 in $2015(25,26)$. In a research, it was revealed that women had the low risk of dying from pregnancyrelated causes in Sri Lanka, Cuba, and Tunisia. These countries provided quality maternal health care and safe abortion services and contraception. Further, they empowered women to take care of their reproductive lives. In this study, the causes of maternal mortality in Tunisia were compared to those in Algeria. The number of women died from pregnancy-related complications in Algeria was twice as large as those in Tunisia. Since the two countries have similar birth practices and contraception usage rate, the best explanation for the observed difference is that Tunisian women have access to safe abortions care whereas Algerian women may threat their lives for terminating a pregnancy (2).

The prevention of maternal mortality is considered as one of the pillars of social righteousness (59). It seems that strategic and comprehensive interventions can prevent maternal deaths (60). However, none of interventions alone can reduce the maternal mortality rate in a population (61). A systematic review reported the positive effects of some interventions on maternal mortality in developing countries (13).

To evaluate different interventions, certain indicators are used. Based on the results, can design and implement appropriate interventions for reducing maternal mortality (37). Providing women's education, reducing fertility rate, and improving child, adult, and family health are the key strategies for terminating preventable maternal and child deaths (28).
Moreover, raising pregnant women's awareness on the danger signs of pregnancy and the postpartum period is essential for decreasing maternal mortality. In an experimental study, it was shown that educational strategies have positive effects on improving the deal of pregnant women's knowledge $(62,63)$.

It is important that a strategic plan can reduce maternal mortality through increasing organizations' resources, as well as its ability to analyze internal and external possibilities and limitations (60). Meda et al suggested that strategic planning can improve the quality of care in hospitals, reduce the mortality rate of hospitalized patients, and improve access to health services (64). The researchers of another study identified five-fold higher risk of maternal death for women who received no prenatal care (18).

The global focus is now on providing women in need with access to life-saving obstetric care. Procedures such as non-medically $\mathrm{C}$-sections and labor inductions among women who do not need them have to be eliminated (65). Running parallel to the declines in maternal mortality, the global coverage of skilled birth attendance increased from $58 \%$ in 1990 to $73 \%$ in 2013 (28).

The specialty promotes the health and well-being of the pregnant woman and her fetus through quality perinatal care. This care entails appropriate recognition and treatment of complications, the supervision of labor and delivery, the assurance of newborn care, and the management of the puerperium. Additionally, postpartum care promotes health and provides families with planning options. Other suggestions for reducing maternal mortality are legal access to abortion services, accessible and affordable contraception measures, and the elimination of harmful practices (2). Similarly, access to skilled birth attendance and essential obstetric care help reduce maternal mortality and morbidity (66). The location where the delivery occurs and how quickly they can be transported to referral-level care are crucial factors. Appropriate intervention requires a considerable deal of skill as well (61).

In summary, mothers' health is one of the MDGs and paying attention to the performance of the obstetric system is a particular importance (67). The best approaches toward this goal include improving hospital service access (68), following up women who did not attend the hospitals (69), as well as focusing on safer motherhood programs and government responsibility in this regard (70). The other approaches encompass increasing the coverage of skilled birth attendance, improving pregnant women's knowledge, increasing the coverage and quality of family planning services, making abortion legal and accessible, eliminating harmful practices, and finally, improving midwifery skills.

\section{Study Limitations}

The number of related studies was low. In addition, the 
authors did not find any article about maternal mortality in Iraq, Libya, Djibouti, and the United Arab Emirates.

\section{Conclusions}

Although all Eastern Mediterranean countries have shown progress in reducing maternal deaths since 1990, MMR in some countries have remained high. To achieve sustainable development goal targets by 2030, a sustained and urgent emphasis on improved pregnancy and childbirth care is required throughout the world. More rapid improvements in maternal mortality require an increased focus on health-care services. Further, high-impact, cost-effective interventions that benefit mothers exist and must be at the focus of health system strengthening and care quality improvement programs. Eventually, efforts to improve maternal health and reduce maternal deaths should emphasize addressing inequalities across and within the countries.

\section{Ethical Issues}

The Ethics Committee of Shahid Beheshti University of Medical Sciences approved the study (ethical No. IR.SBMU.RETECH.REC.1396.457)

\section{Conflict of Interests}

The authors declare that they have no conflict of interests.

\section{Financial Support}

"Student Research Committee" and "Research and Technology Chancellor" of Shahid Beheshti University of Medical Sciences, Tehran, Iran.

\section{Acknowledgements}

The authors would like to appreciate the "Student Research Committee" and "Research and Technology Chancellor" of Shahid Beheshti University of Medical Sciences for their financial support (project No. 1396/34264) of this study. In addition, special appreciation goes to all those how helped to complete this research.

\section{References}

1. Arfaie K, Nahidi F, Simbar M, Bakhtiari M. Exploring socio-cultural factors surrounding pregnancy anxiety in Iranian women: a qualitative study. Int J Humanit Cult Stud. 2016;3(2):198-210.

2. Coeytaux F, Bingham D, Langer A. Reducing maternal mortality: a global imperative. Contraception. 2011;83(2):95-98. doi:10.1016/j.contraception.2010.10.009

3. Centers for Disease Control and Prevention (CDC). Pregnancy-Related Deaths. https://www.cdc.gov/ reproductivehealth/maternal-mortality/preventingpregnancy-related-deaths.html. Accessed 9 Jan 2020.

4. Sarpong S. Modeling and forecasting maternal mortality; an application of ARIMA models. Int J Appl Sci Technol. 2013;3(1):19-28.

5. World Health Organization (WHO). Trends in maternal mortality: 1990 to 2010 -- WHO, UNICEF, UNFPA and
The World Bank estimates. https://www.who.int/reproductivehealth/publications/monitoring/9789241503631/en/. Published 2012.

6. United Nations Development Programme (UNDP). Human Development Report 2015: work for human development. http://www.hdr.undp.org/en/content/human-development-report-2015. Published 2015.

7. Langlois ÉV, Miszkurka M, Zunzunegui MV, Ghaffar A, Ziegler D, Karp I. Inequities in postnatal care in low- and middle-income countries: a systematic review and metaanalysis. Bull World Health Organ. 2015;93(4):259-270G. doi:10.2471/blt.14.140996

8. Say L, Chou D, Gemmill A, et al. Global causes of maternal death: a WHO systematic analysis. Lancet Glob Health. 2014;2(6):e323-333. doi:10.1016/s2214-109x(14)70227-x

9. Nafiu LA, Aau'ud AA, Adiukwu RN. Determinants of maternal mortality in Somalia. Pac J Sci Technol. 2016;17(2):318-328.

10. Millennium-project. Goals, targets and indicators. http:// www.millennium-project.org/. Accessed 9 Jan 2020.

11. Roozbeh N, Nahidi F, Hajiyan S. Barriers related to prenatal care utilization among women. Saudi Med J. 2016;37(12):1319-1327. doi:10.15537/smj.2016.12.15505

12. United Nations Development Programme (UNDP). Sustainable Development Goals. https://www.undp.org/ content/undp/en/home/sustainable-development-goals. html. Accessed 9 Jan 2020

13. Khan KS, Wojdyla D, Say L, Gülmezoglu AM, Van Look PF. WHO analysis of causes of maternal death: a systematic review. Lancet. 2006;367(9516):1066-1074. doi:10.1016/ s0140-6736(06)68397-9

14. World Health Organization (WHO). Indicator and monitoring framework for the Global Strategy for Women's, Children's and Adolescents' Health (2016-2030). https://www.who.int/life-course/about/coia/indicator-andmonitoring-framework/en/. Accessed 9 Jan 2020.

15. World Health Organization (WHO). World Health Statistics 2016: Monitoring Health for the SDGs Sustainable Development Goals. https://www.who.int/gho/ publications/world_health_statistics/2016/en/. Accessed 9 Jan 2020.

16. Alshishtawy MM. Strategic approach to improving maternal survival in oman. Oman Med J. 2008;23(3):179-186.

17. UNFPA. Maternal health. https://www.unfpa.org/maternalhealth. Accessed 9 Jan 2020.

18. Cunningham F, Leveno K, Bloom S, Spong CY, Dashe J. Williams Obstetrics. 24th ed. New York: McGraw-Hill Education; 2014.

19. Gholami-Taramsari M. Ten-Year Evaluation of maternal mortalities in Kohgiluyeh and Boyerahmad province. Knowledge \& Health. 2008;3(2):33-37. [Persian].

20. Clark SL, Belfort MA, Dildy GA, Herbst MA, Meyers JA, Hankins GD. Maternal death in the 21st century: causes, prevention, and relationship to cesarean delivery. Am J Obstet Gynecol. 2008;199(1):36.e31-35. doi:10.1016/j. ajog.2008.03.007

21. Gheit SA, Noah O, Shoukry M, Sedky M. Maternal mortality rate: a tertiary care university hospital experience. Evid Based Women Health J. 2012;2(2):64-67. doi:10.1097/01. EBX.0000413058.28135.7f

22. Karimi-Zarchi M, Ghane-Ezabadi M, Vafaienasab M, et al. Maternal mortality in Yazd Province, Iran. Electron Physician. 2016;8(2):1949-1954. doi:10.19082/1949 
23. World Health Organization (WHO). WHO regional offices. https://www.who.int/about/who-we-are/regional-offices. Accessed 10 Jan 2020.

24. World Health Organization (WHO). ICD-10, International statistical classification of diseases and related health problems. https://www.who.int/classifications/icd/ ICD10Volume2_en_2010.pdf. Accessed 10 Jan 2020.

25. World Health Organization (WHO). Countries. WHO statistical profile 2015. https://www.who.int/docs/defaultsource/gho-documents/world-health-statistic-reports/ world-health-statistics-2015.pdf?sfvrsn=afb0629f_2. Accessed 10 Jan 2020.

26. World Health Organization (WHO). Eastern Mediterranean Region-Framework for health information systems and core indicators for monitoring health situation and health system performance. Cairo: WHO Regional Office for the Eastern Mediterranean; 2016.

27. World Bank. Country Income Groups. http://blogs. worldbank.org/opendata/new-country-classificationsincome-level-2019-2020. Accessed 10 Jan 2020.

28. World Health Organization (WHO). Health in 2015: from MDGs, Millennium Development Goals to SDGs, Sustainable Development Goals. Geneva: WHO; 2015.

29. Gökengin D, Doroudi F, Tohme J, Collins B, Madani N. HIV/AIDS: trends in the Middle East and North Africa region. Int J Infect Dis. 2016;44:66-73. doi:10.1016/j. ijid.2015.11.008

30. UNFPA. The state of the world's midwifery 2014: a universal pathway, a woman's right to health. https://www.unfpa.org/ sowmy. Published 2014.

31. Zolala F, Haghdoost AA. A gap between policy and practice: a case study on maternal mortality reports, Kerman, Iran. Int J Prev Med. 2011;2(2):88-93.

32. Moradi-Lakeh M. More realistic estimate for maternal mortality ratio in Iran. Iran J Public Health. 2011;40(3):141142.

33. Moazzeni MS. Maternal mortality in the Islamic Republic of Iran: on track and in transition. Matern Child Health J. 2013;17(4):577-580. doi:10.1007/s10995-012-1043-6

34. Rajaee M, Zare S, Dadipour S, et al. Determining the frequency and causes of maternal mortality in Hormozgan Province, Iran during 2005-2011. The Iranian Journal of Obstetrics, Gynecology and Infertility. 2014;16(87):9-14. [Persian].

35. Mohammadinia N, Samiezadeh Toosi T, Rezaei MA, Rostaei F. Investigating the frequency and effective factors on maternal mortality in Sistan and Baluchistan Province, Iran, 2002-2009. The Iranian Journal of Obstetrics, Gynecology and Infertility. 2013;16(44):28-34. doi:10.22038/ijogi.2013.653

36. Maharlouei N, Zakeri Z, Mazloomi E, Lankarani KB. Maternal mortality rate in Fars Province: trends and associated factors in a community-based survey. Arch Iran Med. 2012;15(1):14-17. doi:012151/aim.006

37. Azemikhah A, Amirkhani MA, Jalilvand P, Emami Afshar N, Radpooyan L, Changizi N. National maternal mortality surveillance system in Iran. Iran J Public Health. 2009;38(Suppl 1):90-92.

38. Hajizadeh S, Tehrani FR, Simbar M, Farzadfar F. Effects of recruiting midwives into a family physician program on women's awareness and preference for mode of delivery and caesarean section rates in rural areas of Kurdistan. PLoS One. 2016;11(4):e0151268. doi:10.1371/journal. pone. 0151268

39. Farrokh-Eslamlou H, Aghlmand S, Oshnouei S. Persistence of hemorrhage and hypertensive disorders of pregnancy (HDP) as the main causes of maternal mortality: emergence of medical errors in Iranian healthcare system. Iran J Public Health. 2014;43(10):1395-1404.

40. Akseer N, Salehi AS, Hossain SM, et al. Achieving maternal and child health gains in Afghanistan: a Countdown to 2015 country case study. Lancet Glob Health. 2016;4(6):e395413. doi:10.1016/s2214-109x(16)30002-x

41. Ahmadi Q, Danesh H, Makharashvili V, et al. SWOT analysis of program design and implementation: a case study on the reduction of maternal mortality in Afghanistan. Int J Health Plann Manage. 2016;31(3):247-259. doi:10.1002/hpm.2288

42. Naim A, Feldman R, Sawyer R. A Needs Assessment of Health Issues Related to Maternal Mortality Rates in Afghanistan: A Pilot Study. Int Q Community Health Educ. 2015;35(3):259-269. doi:10.1177/0272684x15575319

43. Sandhu AK, Mustafa FE. Maternal mortality in Bahrain 1987-2004: an audit of causes of avoidable death. East Mediterr Health J. 2008;14(3):720-730.

44. Saleh WF, Ragab WS, Aboulgheit SS. Audit of maternal mortality ratio and causes of maternal deaths in the largest maternity hospital in Cairo, Egypt (Kasr Al Aini) in 2008 and 2009: lessons learned. Afr J Reprod Health. 2013;17(3):105-109.

45. El Daba AA, Amr YM, Marouf HM, Mostafa M. Retrospective study of maternal mortality in a tertiary hospital in Egypt. Anesth Essays Res. 2010;4(1):29-32. doi:10.4103/0259-1162.69303

46. Chibber R, Al-Hijji J, Al-Adwani AR, et al. Trends in maternal mortality over 29 years in a Kuwait Tertiary Teaching Hospital: signs of progress? J Matern Fetal Neonatal Med. 2012;25(9):1557-1563. doi:10.3109/147670 58.2011 .640373

47. Abouchadi S, Alaoui AB, Meski FZ, Bezad R, De Brouwere V. Preventable maternal mortality in Morocco: the role of hospitals. Trop Med Int Health. 2013;18(4):444-450. doi:10.1111/tmi.12065

48. Islam MM, Bakheit CS. Advanced maternal age and risks for adverse pregnancy outcomes: a population-based study in Oman. Health Care Women Int. 2015;36(10):1081-1103. doi:10.1080/07399332.2014.990560

49. Agha S. A profile of women at the highest risk of maternal death in Pakistan. Health Policy Plan. 2015;30(7):830-836. doi:10.1093/heapol/czu066

50. Bano N, Chaudhri R, Yasmeen L, Shafi F, Ejaz L. A study of maternal mortality in 8 principal hospitals in Pakistan in 2009. Int J Gynaecol Obstet. 2011;114(3):255-259. doi:10.1016/j.ijgo.2011.03.018

51. Rahman S, Latiph E, Nimeri N, et al. Maternal Mortality Ratio and Universal Access to Reproductive Health Care in the State of Qatar between 1990 and 2012: A PEARL Study Analysis. Int J Gynecol Obstet Neonatal Care. 2016;3(2):2633. doi:10.15379/2408-9761.2016.03.02.01

52. Al-Suleiman SA, Al-Sibai MH, Al-Jama FE, El-Yahia AR, Rahman J, Rahman MS. Maternal mortality: a twenty-year survey at the King Faisal University Hospital, Al-Khobar, Eastern Saudi Arabia. J Obstet Gynaecol. 2004;24(3):259263. doi:10.1080/01443610410001660742

53. Sorbye IK. A situation analysis of reproductive health in Somalia. UNFPA, WHO, UNICEF; 2009.

54. Taha U, Ismail S, AbdAlla E, Alilah K, Eltahir S, Mirghani S. 
Reducing Maternal Mortality from Direct Obstetric Causes during 2013 in Sudan. Journal of US-China Medical Science. 2014;11:212-218. doi:10.17265/1548-6648/2014.04.006

55. Elhassan E, Hassan A, Haggaz A, Ali A, Adam I. Epidemiology of maternal mortality and poor perinatal outcomes in the different regions of Sudan. Gezira Journal of Health Sciences. 2010;6(1):1-8.

56. Almerie MQ, Matar HE, Almerie Y. A 20-year (19892008) audit of maternal mortality in Damascus, Syria. Int J Gynaecol Obstet. 2011;112(1):70-71. doi:10.1016/j. ijgo.2010.08.007

57. Bashour H, Abdulsalam A, Jabr A, et al. Maternal mortality in Syria: causes, contributing factors and preventability. Trop Med Int Health. 2009;14(9):1122-1127. doi:10.1111/ j.1365-3156.2009.02343.x

58. Bashour H, Saad-Haddad G, DeJong J, et al. A cross sectional study of maternal 'near-miss' cases in major public hospitals in Egypt, Lebanon, Palestine and Syria. BMC Pregnancy Childbirth. 2015;15:296. doi:10.1186/ s12884-015-0733-7

59. Naghizadeh S, Azari S, Mohammady F, Ebrahimpour Mirza Rezaei M, Sehhati F. Maternal Satisfaction about Prenatal and Postnatal Cares in Vaginal and Cesarean Section Delivery at Teaching and Non-teaching Hospitals of Tabriz/Iran. Int J Women's Health Reproduction Sci. 2014;2(3):146-154. doi:10.15296/ijwhr.2014.22

60. Nosraty S, Rahimi M, Kohan S, Beigei M. Effective strategies for reducing maternal mortality in Isfahan University of Medical Sciences, 2014. Iran J Nurs Midwifery Res. 2016;21(3):310-316. doi:10.4103/1735-9066.180391

61. Campbell OM, Graham WJ. Strategies for reducing maternal mortality: getting on with what works. Lancet. 2006;368(9543):1284-1299. doi:10.1016/s01406736(06)69381-1

62. Gebrehiwot H, Bahta S, Haile N. Awareness of danger signs of pregnancy and its associated factors among pregnant women who visit ANC in Mekelle public hospitals. Am J Adv Drug Deliv. 2014;2(2):164-173.

63. Rajabi Naeeni M, Farid M, Tizvir A. A comparative study of the effectiveness of multimedia software and face-toface education methods on pregnant women's knowledge about danger signs in pregnancy and postpartum. J Educ Community Health. 2015;2(1):50-57. [Persian].

64. Meda ZC, Konate L, Ouedraogo H, Sanou M, Hercot D, Sombie I. [Leadership and vision in the improvement of universal health care coverage in low-income countries]. Sante. 2011;21(3):178-184. doi:10.1684/san.2011.0268

65. Zhang J, Troendle J, Reddy UM, et al. Contemporary cesarean delivery practice in the United States. Am J Obstet Gynecol. 2010;203(4):326.e321-326.e310. doi:10.1016/j. ajog.2010.06.058

66. World Health Organization (WHO). Standards for improving quality of maternal and newborn care in health facilities. https://www.who.int/maternal_child_adolescent/ documents/improving-maternal-newborn-care-quality/ en/. Published 2016.

67. Sereshti M, Nahidi F, Simbar M, Ahmadi F, Bakhtiari M, Zayeri F. Mothers' perception of quality of services from health centers after perinatal loss. Electron Physician. 2016;8(2):2006-2017. doi:10.19082/2006

68. Simbar M, Nahidi F, Dolatian M, Akbarzadeh A. Assessment of quality of prenatal care in Shahid Beheshti Medical Science University centers. Int J Health Care Qual Assur. 2012;25(3):166-176. doi:10.1108/09526861211210394

69. Clouse K, Pettifor A, Shearer K, et al. Loss to followup before and after delivery among women testing HIV positive during pregnancy in Johannesburg, South Africa. Trop Med Int Health. 2013;18(4):451-460. doi:10.1111/ tmi.12072

70. Costello A, Azad K, Barnett S. An alternative strategy to reduce maternal mortality. Lancet. 2006;368(9546):14771479. doi:10.1016/s0140-6736(06)69388-4

(c) 2020 The Author (s); This is an open-access article distributed under the terms of the Creative Commons Attribution License (http://creativecommons.org/licenses/by/4.0), which permits unrestricted use, distribution, and reproduction in any medium, provided the original work is properly cited. 